\title{
The effect of guar gum on the distribution of a radiolabelled meal in the gastrointestinal tract of the rat
}

\author{
BY NICOLA J. BROWN, JANE WORLDING, R. D. E. RUMSEY \\ AND N. W. READ* \\ Sub-Department of Human Gastrointestinal Physiology and Nutrition, Physiology \\ Department, University of Sheffield, Western Bank, Sheffield S10 2TN
}

(Received 13 April 1987 - Accepted 22 September 1987)

1. The effect of addition of guar gum ( 5 and $10 \mathrm{~g} / \mathrm{l}$ ) to a radiolabelled, homogenized, baked-bean test meal on the distribution of that meal in the gastrointestinal tract was investigated in groups of male rats killed at 25,50 , $100,200,300$ and $400 \mathrm{~min}$ after gavage.

2. Addition of 5 and $10 \mathrm{~g}$ guar gum/l significantly increased the proportion of the meal remaining in the stomach at 25 and 50 min after gavage $(P<0.01)$.

3. The heads of the control meal and meals containing guar gum reached the distal small intestine within 25 min after gavage but radioactivity was not observed in the caecum until 100 min after administration of each of the meals. Addition of guar gum $(5$ and $10 \mathrm{~g} / 1)$ delayed caecal filling even though the head of each meal reached the caecum at the same time after gavage.

4. The geometric centres of guar-gum-containing meals were proximal to that of the control meal at all times after gavage.

5. The observed delay in the passage of a guar-gum-containing meal through the stomach and small intestine is probably due to the viscous nature of the meal resisting the propulsive and mixing effects of the gastrointestinal contractions, thereby reducing access of the glucose to the absorptive epithelium. This could contribute to the observed reductions in postprandial glycaemia seen in previous studies after incorporating guar gum into a meal.

Guar gum is a polysaccharide which cannot be digested in the human small intestine. When incorporated into a carbohydrate-rich test meal or oral glucose load, it forms a viscous solution (Lewis, 1978) which retards the absorption of carbohydrate (Jenkins et al. 1976; Jenkins, 1983) and cholesterol (Kahn et al. 1981) from the human small intestine. This lowers postprandial glycaemia in normal and diabetic humans (Jenkins et al. 1976; Morgan, 1979). Plasma insulin is also lowered partly in response to the reduction in blood glucose levels and partly due to a reduction in the release of glucose insulinotrophic polypeptide from the duodenal and jejunal mucosa (Morgan et al. 1979). Guar gum has also been shown to reduce the absorption of triglycerides (Schell et al. 1985), cycloleucine, taurocholate, methyl-D-glucoside and urea (Elsenhans et al. 1984) from the rat small intestine. The mechanism responsible for these effects, however, remains unclear. Absorption may be slowed either because the viscous meals are delivered to the small intestine more slowly (Leeds et al. 1978; Holt et al. 1979; Blackburn et al. 1984a, b; Russell $\&$ Bass, 1985), because they remain in a smaller area of the small intestine for much of the postprandial period (Bueno et al. 1981; Forman \& Schneeman, 1982), or because they are distributed preferentially to a region such as the ileum that normally absorbs nutrients more slowly. The aim of the present experiments was to investigate whether guar gum affected the way in which the meal was distributed along the small intestine, since altered distribution may affect meal absorption.

Guar gum is used in the food industry as a thickener and stabilizer. In confectionery, frozen desserts, salad cream, etc. it is used in concentrations between 2 and $20 \mathrm{~g} / 1$ (Bowes \& Church, 1975). In these studies guar gum was incorporated into a semisolid meal at concentrations of 5 and $10 \mathrm{~g} / \mathrm{l}$. The results indicate that guar gum slowed the passage of

* For reprints. 
a semi-solid meal from the stomach to the small intestine and through both the jejunum and ileum, probably by resisting the propulsive effects of gastrointestinal contractions. These effects could contribute to the observed reduction in postprandial glycaemia after incorporation of guar gum into a carbohydrate meal (Blackburn et al. 1984b).

\section{MATERIALS AND METHODS}

\section{Animals}

Experiments were carried out using 108 male albino rats, Sheffield strain, weighing between 250 and $300 \mathrm{~g}$. Rats were caged in groups of four, and allowed free access to food (Diet 86; Oxoid, London) and water until $18 \mathrm{~h}$ before the experiment when they were fasted.

\section{Study design}

Three groups of thirty-six rats were given meals consisting of $5 \mathrm{ml}$ homogenized baked beans containing either 0,5 or $10 \mathrm{~g}$ guar gum/l. Baked beans were chosen as a suitable test meal because they are similar to the normal constituents of the rat diet, they contain sufficient unabsorbed carbohydrate and fibre to maintain the bulk of the luminal contents and they are easily homogenized to give to the rats by tube. To prepare the meals, baked beans were strained free of syrup, homogenized and diluted to $200 \%$ (w/v) of their original volume by addition of water. ${ }^{99 \mathrm{~m}} \mathrm{Technetium}\left({ }^{99 \mathrm{~m}} \mathrm{Tc} ; 25 \mu \mathrm{Ci}\right.$ )-sulphur colloid (Amersham International plc, Amersham, Bucks) was added to the water used to homogenize the beans. Since the meals were of homogeneous consistency, it is likely that the marker provided an index of the movement of the combined liquids and solids through the stomach and small intestine (Hinder \& Kelly, 1977; Malagelada et al. 1979). Guar gum (Hercules Powder Co. Erith, Kent) was added to the homogenates and the mixture was continuously stirred for $1 \mathrm{~h}$ before gavage, so that maximum viscosity (J. Tomlin, personal communication) and intimate mixing were obtained (Jenkins et al. 1976). The control meal without guar gum was prepared in the same way. The viscosities of the three meals were measured using a Contraves Epprecht-Rheosmat 15 Viscometer (Contraves, Zurich, Switzerland). The viscosities of the baked-bean meal, the baked-bean and $5 \mathrm{~g}$ guar gum/ 1 meal, and the baked-bean and $10 \mathrm{~g}$ guar gum $/ 1$ meal were 372,1429 and $2806 \mathrm{mPas}$ respectively.

All the animals used in the study were fed by gavage. Each group of thirty-six rats was subdivided into six subgroups, which were killed at intervals of $25,50,100,200,300$ and $400 \mathrm{~min}$ after gavage, by exposure to cyclopropane gas $(800-900 \mathrm{ml} / 1$; B.O.C. Gases Ltd., Rotherham) in a closed chamber. Surgical anaesthesia was rapidly obtained and death occurred within $30 \mathrm{~s}$ without causing any obvious signs of trauma to the internal organs (Paton \& Payne, 1968; Atkinson \& Lee, 1973).

After death, the digestive tract was ligated at the lower oesophageal sphincter, the pylorus and the ileo-caecal valve, completely removed from the animal and transferred to a longitudinal perspex trough. Care was taken in handling the intestine to avoid stretching and displacement of luminal contents. The trough was pulled by an electric motor at a rate of $100 \mathrm{~mm} / \mathrm{min}$ at a constant depth of $46 \mathrm{~mm}$ under a crystal scintillation detector (type DMI-2 Nuclear Enterprises Ltd., Edinburgh), fitted with a $6 \mathrm{~mm}$ slit collimator and connected to a counter ratemeter (type MS 310E, J \& P Engineering Ltd., Reading). The resultant radioactivity profile (Fig. 1) was displayed on a chart recorder also running at a speed of $100 \mathrm{~mm} / \mathrm{min}$. The remainder of the carcass was monitored using a scintillation meter (type 5-40; Mini-Instruments Ltd., Essex) to ensure all radiation used was contained within the excised gastrointestinal tract. 

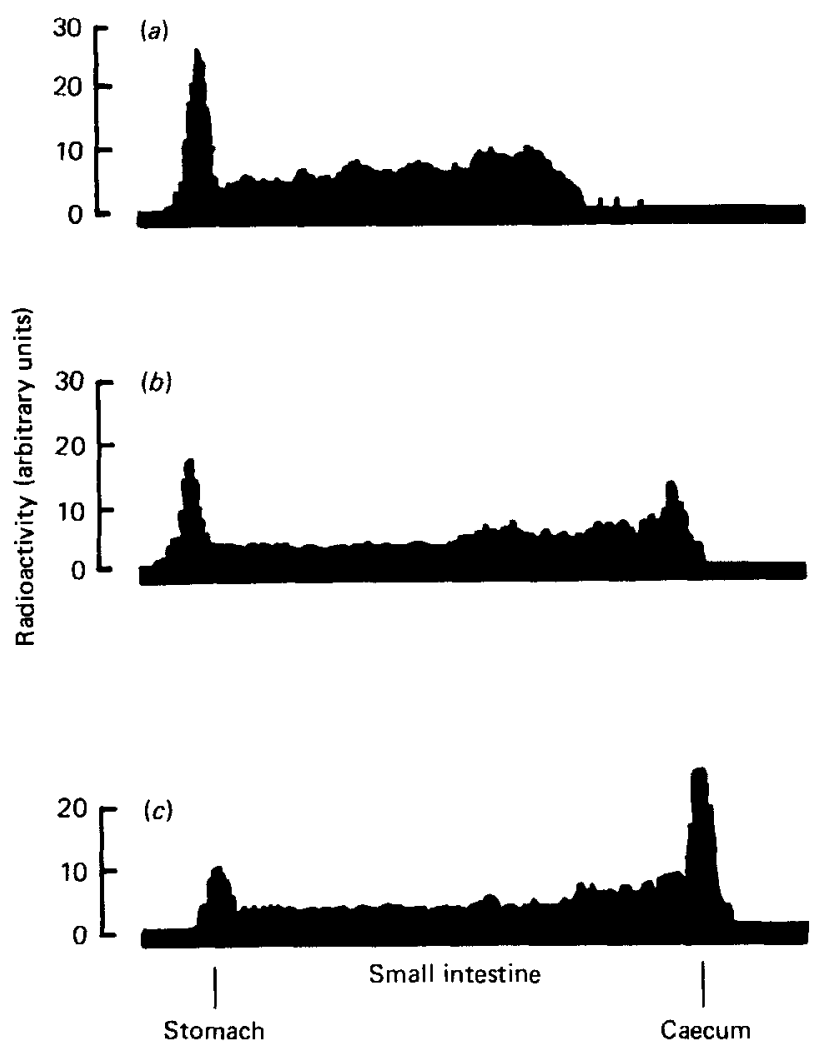

Fig. 1. A diagram to illustrate the typical distribution of a radiolabelled meal in the gastrointestinal tract of rats killed at $(a) 50,(b) 100$, and $(c) 200$ min after gavage. For details of the test meal, see p. 224.

\section{Analysis of radioactivity profiles}

The radioactivity profiles from the chart recorder (Fig. 1) were divided into twelve sections. These consisted of stomach, caecum and ten equal sections of small intestine from the pylorus to the ileocaecal valve. The area under each section was determined gravimetrically and expressed as a percentage of the total area of the radioactivity profile. Histograms were constructed of the percentage of radioactivity in each of the twelve sections at different times after each meal (Fig. 2). In addition, some of the data were pooled to provide information on the distribution of the meal in the duodenum (section 1), proximal (sections 2-4), mid (sections 5-7) and distal (sections 8-10) small intestine. Integrating the distribution data with time yielded values for residence of the meal marker in each region (Fig. 3).

The 'geometric centre' of the gastrointestinal distribution of ${ }^{89 \mathrm{~m}} \mathrm{Tc}$-sulphur colloid at each time interval for each meal was calculated from the following equation (Miller $e t a l$. 1981):

$$
\text { Geometric centre }=\text { sum of (fraction }{ }^{99 \mathrm{~m}} \mathrm{Tc} / \text { segment } \times \text { segment number). }
$$

\section{Statistical analysis}

Results are expressed as means and standard error of the means. The degree of statistical significance was assessed using the Mann-Whitney $U$ test for non-parametric data. 

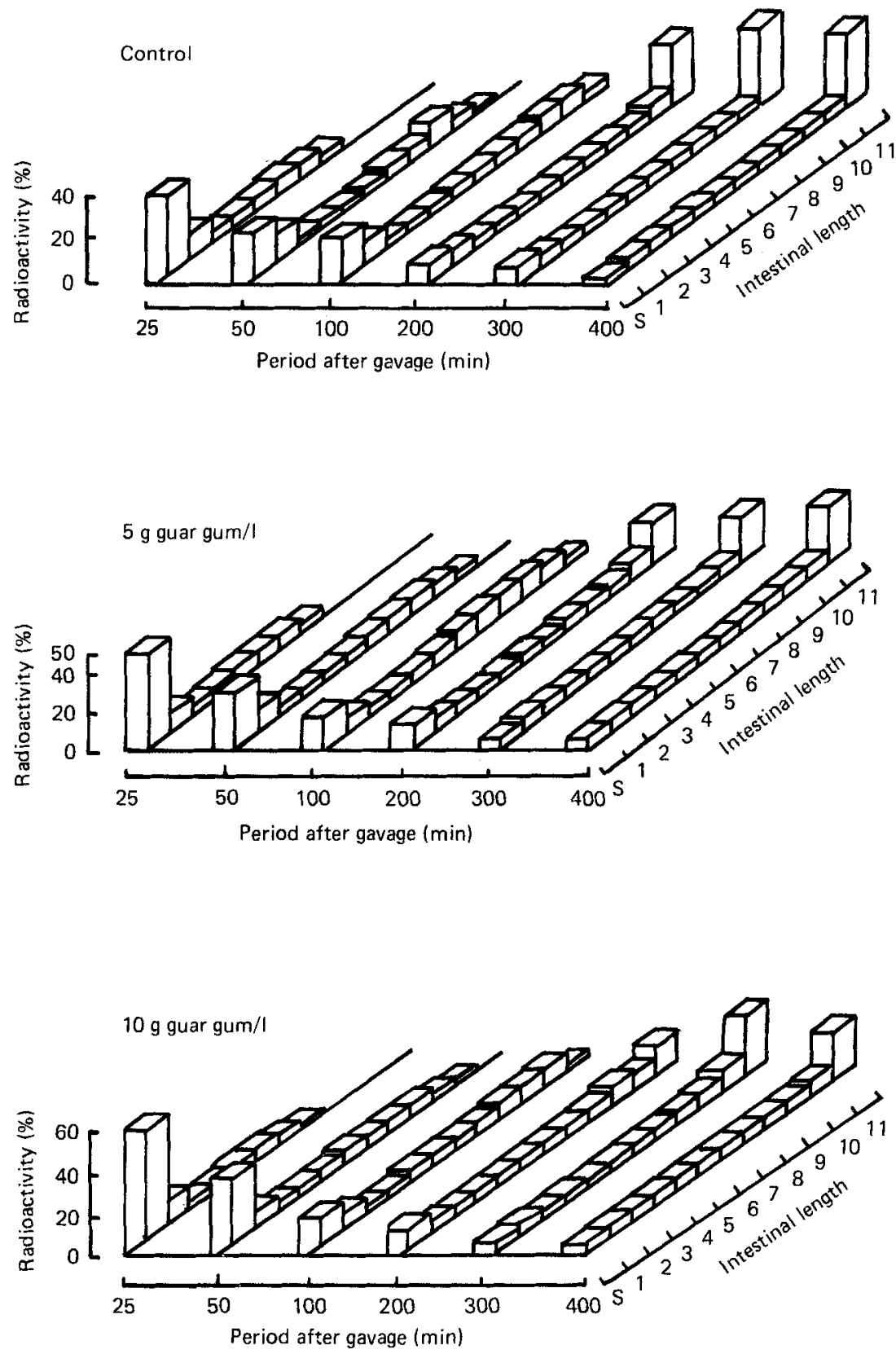

Fig. 2. Three-dimensional histograms indicating the distribution of a radioactive meal along the intestinal length for each time interval after gavage $(25,50,100,200,300$ and $400 \mathrm{~min})$, when the rats were killed. Section $\mathrm{S}$, stomach; section 1, duodenum; sections 2-4, proximal small intestine; sections 5-7, mid small intestine; sections 8-10, distal small intestine; section 11, caecum and colon. Histograms show the distributions of radioactive marker within the intestine obtained after control and test meals $(0,5$ and $10 \mathrm{~g}$ guar gum/l), each block being a mean of six individual values. For details of test meals, see p. 224. 

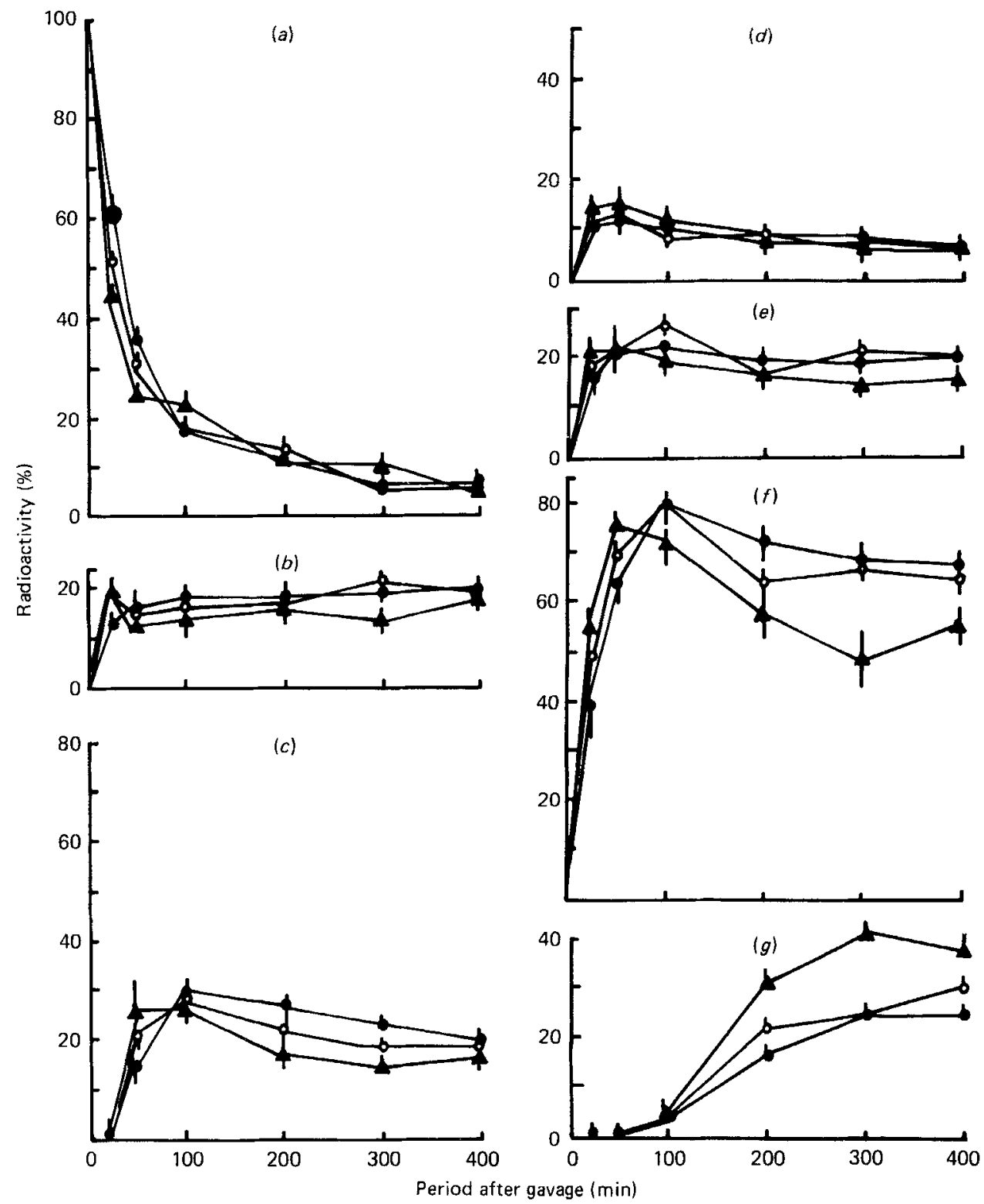

Fig. 3. The residence time of the radiolabelled meal within each section of the gastrointestinal tract: $(a)$ stomach, $(b)$ duodenum, $(c)$ proximal small intestine, $(d)$ mid small intestine, $(e)$ distal small intestine, $(f)$ total small intestine, $(g)$ caecum and colon. Each point indicates the percentage of radioactive marker present at each time-interval after gavage $(25,50,100,200,300$ and $400 \mathrm{~min})$ when the rats were killed. (A), Control; (O), 5 g guar gum/1; (O), 10 g guar gum/l. Points are means, with their standard errors represented by vertical bars, for six rats. For details of test meals, see p. 224.

\section{RESULTS}

Gastric emptying

The incorporation of either 5 or $10 \mathrm{~g}$ guar gum $/ 1$ into the meal significantly increased the amount of the meal retained in the stomach at 25 and 50 min after gavage $(P<0.01)$ (Fig. $3)$. From these values, calculated values for half-time gastric emptying were significantly 


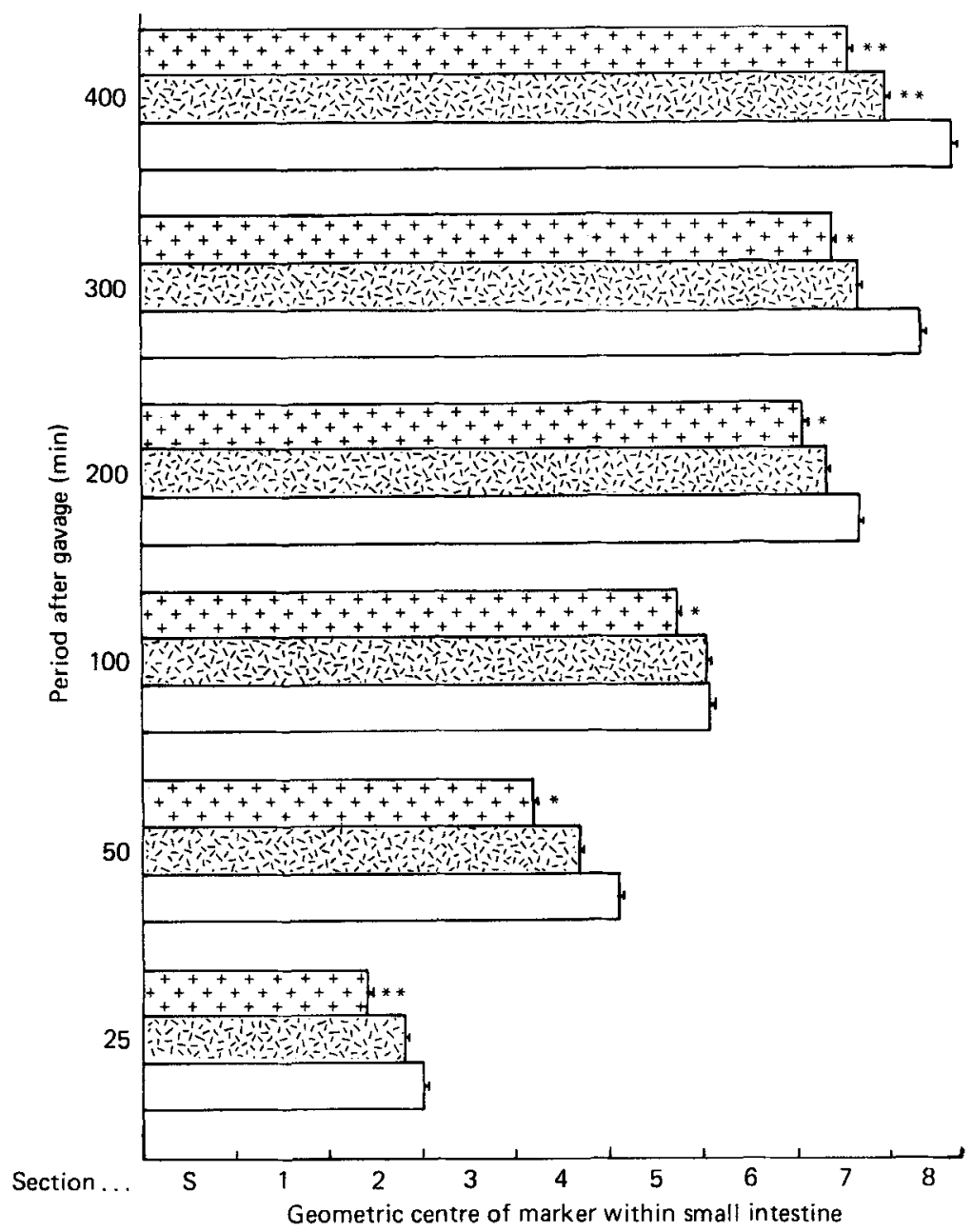

Fig. 4. The geometric centres for each meal and for each time interval after gavage $(25,50,100,200$, $300,400 \mathrm{~min}$ ) when the rats were killed. Section $S$, stomach; section 1, duodenum; sections $2-4$, proximal small intestine; sections 5-7, mid small intestine; section 8, beginning of distal small intestine. Values are means, with their standard errors represented by horizontal bars, for six rats. $\square$, Control; 因, $5 \mathrm{~g}$ guar $\operatorname{gum} / 1 ; \mp, 10 \mathrm{~g}$ guar gum/1. ${ }^{*} P<0.05 ;{ }^{* *} P<0.001$.

longer for meals containing $5 \mathrm{~g}$ guar gum/1 (mean 53 (SE 4) min, $P<0.01$ ) and $10 \mathrm{~g}$ guar gum $/ 1$ (mean 65 (SE 4) min, $P<0.001$ ) than for the control meal (mean 32 (SE 5) min).

\section{Small intestinal transit and residence}

The head of the meal had reached the end of the mid small intestine (section 7) within $25 \mathrm{~min}$, the end of the distal small intestine (section 10) within $50 \mathrm{~min}$ and the caecum within $100 \mathrm{~min}$ after gavage (Figs 2 and 3), irrespective of the composition of the meal. Addition of either 5 or $10 \mathrm{~g}$ guar gum $/ 1$ to the control meal reduced the amount of meal marker in the duodenum (section 1) at 25,50 and $100 \mathrm{~min}$ after gavage, probably due to the delay in gastric emptying (Figs 2 and 3).

At $50 \mathrm{~min}$ after gavage, relatively greater amounts of radioactivity were present in the 
upper small intestine (sections 2-5) after the meals that contained guar gum compared with the control meals, and smaller amounts of radioactivity were present in the distal small intestine (sections 8-10) (Fig. 3). However 5-6 h later at 300 and $400 \mathrm{~min}$ after gavage more radioactivity was present in part of the mid and distal sections (6-10) of the small intestine $(P<0.05$,), after the guar-gum meals compared with the control meal (Fig. 3).

The geometric centres of the distribution of radioactivity from the meals containing guar gum were delayed at all times when compared with the control meal (Fig. 4), but only the differences between the control and the $10 \mathrm{~g}$ guar gum/l meals were statistically significant.

Addition of either 5 or $10 \mathrm{~g}$ guar gum/l to the meal increased the residence time of the meal marker in the small intestine as a whole, and in the proximal, mid and distal segments of the small intestine $(P<0.01)$ (Fig. 3). The residence time of the marker in the distal small intestine was greater, however, than in the proximal small intestine irrespective of the meal (control, $P>0.05 ; 5 \mathrm{~g}$ guar gum $/ 1, P<0.05 ; 10 \mathrm{~g}$ guar gum $/ 1, P<0.001$ ).

\section{Caecum}

There was significantly less radioactivity present in the caecum of animals fed on meals containing guar gum than in those fed on the control meal at 200,300 and 400 min after gavage (Figs 2 and 3), even though greater proportions of the guar-gum meals than the control meal were in the ileum at those times and the heads of each of the meals had arrived at the caecum at the same time. Thus the rate of caecal filling was slowed after administration of the guar-gum meals $(5 \mathrm{~g}$ guar gum $/ 1, P<0.01 ; 10 \mathrm{~g}$ guar gum $/ 1$, $P<0.001$ ) (Fig. 3).

\section{DISCUSSION}

The results from this study show that the incorporation of guar gum into a radiolabelled semisolid meal of homogeneous consistency delayed the delivery of the meal marker from the stomach into the small intestine and from the small intestine into the colon. However, the effect of this viscous polysaccharide on stomach to caecum transit time did not occur just as a consequence of the delayed gastric emptying. The small-intestinal residence time of the marker was much greater for the meals containing guar gum than that for the control meal, despite the probability that guar gum would reduce absorption of the meal (Blackburn et al. 1984b), thereby preventing reduction in luminal volume and potentially stimulating peristalsis (Trendelenberg, 1917). Also caecal filling was slower after guar-gum meals even though the results suggest that the bulk of the ileal contents was greater.

The observation that gastric emptying, small-bowel transit time and caecal filling are all delayed by guar gum is compatible with the concept, supported by many workers, that viscous luminal contents resist the propulsion by gastrointestinal contractions. Studies have shown that although viscous meals are associated with a greater frequency of propagated antral pressure-waves than non-viscous meals (Bueno et al. 1981), gastric emptying is in fact slower (Holt et al. 1979; Erhlein \& Prove, 1982; Forman \& Schneeman, 1982; Russell $\&$ Bass, 1985). Similarily, although guar-gum-containing meals induce highly propagated motor complexes in the human small intestine (Welch \& Worlding, 1986), transit is slowed (Blackburn et al. 1984a). It has also been shown in an in vitro model using isolated smallintestinal segments that guar gum, between concentrations of 7.5 and $20 \mathrm{~g} / 1$ in Krebs buffer, reduced the volume propelled from the segment compared with the volume of Krebs buffer alone propelled from the same segment (Fisher et al. 1986), despite an increased contractile response of the segment in the presence of guar gum. These results suggest that guar gum slows the transit of a meal by resisting the effect of propagative contractions.

The increase in small-bowel residence time induced by incorporation of guar gum into 
the meal comprises an increase in the residence time of the guar-gum meals in all segments of the small intestine. However, the studies showed clearly that for all meals the residence of the marker was greater in the distal segments than in the proximal segments. The head of the meal took only 25 min to reach the distal small intestine, but four times as long to reach the caecum. The results resemble those obtained using scintigraphy in human volunteers (Jian et al. 1984; Read et al. 1986). The delay in transit in the ileum may reflect the decrease in bulk of the meal that had occurred by the time it had reached the distal segments of the small intestine, and the relative concentration of the meal marker. On the other hand, previous studies have shown that the transit of infused solutions or capsules is slower in the ileum than in the jejunum (Connell, 1961; Morris \& Turnberg, 1980), suggesting that the ileum normally exhibits less propulsive activity than the jejunum, as confirmed by recent manometric studies (Kerlin \& Phillips, 1982).

Despite the delay in small-intestinal transit of the bulk of the meal containing guar gum, each of the meals appeared to reach the ileum and the caecum around the same time. Bearing in mind the lack of precision of the methodology, the results suggest that methods that measure transit of the head of the meal, such as the breath hydrogen technique (Read et al. 1980; Brown et al. 1987), may not give an accurate index of transit of the bulk of the meal to the caecum.

It is probable that the slowing in the passage of food through the upper gastrointestinal tract could contribute to the reduction in postprandial glycaemia obtained in other studies. Three effects are important: (1) the slower gastric emptying could reduce the delivery of the nutrients to the absorptive site, (2) the delay in the passage through the upper small intestine could reduce the area of contact between the nutrients and the small intestinal epithelium, (3) the viscosity of the guar-gum meals could delay the access of glucose to the intestinal epithelium. However, in previous studies carried out in humans, we were unable to demonstrate any relation between the gastric emptying of carbohydrate meals containing guar gum and the postprandial rise in blood sugar (Blackburn et al. 1984b). Moreover, confining glucose solutions to a limited region of the upper small intestine in humans only caused a small reduction in blood sugar levels (Blackburn et al. 1984a). These observations would suggest that the anti-propulsive actions of guar gum may have a relatively small effect on postprandial glycaemia. Guar gum did, however, reduce the glucose uptake in tied loops of rat small intestine (L. Craigen and N. W. Read, unpublished observations) and perfused loops of human small intestine (Blackburn et al. 1984 b), suggesting that the access of glucose to the epithelium is hindered by making the intestinal contents more viscous with guar gum. This is probably related to the inhibition of the mixing effect of intestinal contractions by viscous solutions (Blackburn et al. $1984 b$; C. A. Edwards and N. W. Read, unpublished observations). Thus both the effects on transit and absorption are compatible with the hypothesis that viscous agents, like guar gum, inhibit the movement of luminal contents caused by intestinal contractions.

The present study was supported by a grant (no. 34137) from the Medical Research Council (UK). The authors thank J. M. Gee (AFRC Institute of Food Research, Norwich) for measuring the viscosity of the samples.

\section{REFERENCES}

Atkinson, R. S. \& Lee, J. A. (1973). A Synopsis of Anaesthesia. Bristol: John Wright.

Blackburn, N. A., Holgate, A. M. \& Read, N. W. (1984a). British Journal of Nutrition 52, 197-204.

Blackburn, N. A., Redfern, J. S., Jarjis, H., Holgate, A. M., Hanning, I., Scarpello, J. H. B., Johnson, I. T. \& Read, N. W. (1984b). Clinical Science 66, 329-336.

Bowes, A. P. \& Church, C. F. (1975). Food Values of Portions Commonly Used, 12th ed. Philidelphia: J. B. Lippincott. 
Brown, N. J., Rumsey, R. D. E. \& Read, N. W. (1987). Gut 28, 849-854.

Bueno, L., Pradduade, F., Fioramonti, J. \& Ruckebusch, Y. (1981). Gastroenterology 80, 701-707.

Connell, A. (1961). Postgraduate Medicine Journal 37, 703-713.

Ehrlein, H.-J. \& Prove, J. (1982). Quarterly Journal of Experimental Physiology 67, 419-425.

Elsenhans, B., Zenker, D. \& Caspary, W. S. (1984). Gastroenterology 86, 645-653.

Fisher, S., Murray, B. E. \& Rumsey, R. D. E. (1986). Journal of Physiology 378, 15 P.

Forman, L. P. \& Schneeman, B. O. (1982). Journal of Nutrition 112, 528-533.

Hinder, R. A. \& Kelly, K. A. (1977). American Journal of Physiology 233, E335-E340.

Holt, S., Heading, R. C., Carter, D. C., Prescott, L. F. \& Tothill, P. (1979). Lancet i, 636-639.

Jenkins, D. J. A. (1983). In Delaying Absorption as a Therapeutic Principle in Metabolic Diseases, pp. 45-56 [W. Creutzfeldt and U. R. Folsch, editors]. New York: Thieme-Stratton.

Jenkins, D. J. A., Leeds, A. R., Wolever, T. M. S., Goff, D. V., Alberti, K. G. M. M., Gassull, M. A. \& Hockaday, T. D. R. (1976). Lancet ii, 172-174.

Jian, R., Najean, Y. \& Bernier, J. J. (1984). Gut 25, 728-731.

Kahn, A. R., Kahn, G. Y., Mitchel, A. \& Quadeer, M. A. (1981). American Journal of Clinical Nutrition 34, 2446-2449.

Kerlin, P. \& Phillips, S. (1982). Gastroenterology 82, $694-700$.

Leeds, A. R., Ralphs, D. N., Boulos, P., Ebeid, F., Metz, G., Dilawari, J. B., Elliot, A. \& Jenkins, D. J. A. (1978). Proceedings of the Nutrition Society 37, 23A.

Lewis, B. A. (1978). American Journal of Clinical Nutrition 31, 582-585.

Malagelada, J. R., Go, V. L. W. \& Summerskill, W. H. J. (1979). Digestive Diseases and Sciences 24, $101-109$

Miller, M. S., Galligan, J. J. \& Burks, T. F. (1981). Journal of Pharmacological Methods 6, 211-217.

Morgan, L. M., Gaulder, T. J., Tsiolakis, D., Marks, V. \& Alberti, K. G. M. M. (1979). Diabetologia 17 , 85-89.

Morris, A. I. \& Turnberg, L. A. (1980). Gastroenterology 79, 861 -866.

Paton, W. M. D. \& Payne, J, P. (1968). Pharmacological Principles and Practices. London: J \& A, Churchill.

Read, N. W., Al-Janabi, M. N., Holgate, A. M. \& Barber, D. C. (1986). Gut 27, 300-308.

Read, N. W., Miles, C. A., Fisher, D., Holgate, A. M., Kime, N. D., Mitchell, M. A., Reeve, A. M., Roche, T. B. \& Walker, M. (1980). Gastroenterology 79, 1276-1282.

Russell, J. \& Bass, P. (1985). American Journal of Physiology 249, G662-G667.

Schell, M., Pacy, J. F. \& Judd, P. A. (1985). Proceedings of the Nutrition Society 44, 17A.

Trendelenberg, P. (1917). Archiv für Experimentelle Pathologie und Pharmakologie 81, 55-129.

Welch, I. McL. \& Worlding, J. (1986). Journal of Physiology 378, 12P. 